\title{
Incidence, Clinical Characteristics, and Long-term Outcome of the Dilated Phase of Hypertrophic Cardiomyopathy
}

\author{
Yoshiyasu Aizawa, Yoko Tanimoto, Yoshiko Hirata, Taishi Fujisawa, Ryoma Fukuoka, Kazuaki Nakajima, \\ Yoshinori Katsumata, Takahiko Nishiyama, Takehiro Kimura, Shinsuke Yuasa, Takashi Kohno, Shun Kohsaka, \\ Mitsushige Murata, Yuichiro Maekawa, Yoshiko Furukawa, Seiji Takatsuki and Keiichi Fukuda \\ Department of Cardiology, Keio University School of Medicine, Tokyo, Japan
}

(Received for publication on March 30, 2018)

(Revised for publication on December 2, 2018)

(Accepted for publication on December 10, 2018)

(Published online in advance on December 29, 2018)

\begin{abstract}
Some patients with hypertrophic cardiomyopathy (HCM) develop systolic dysfunction, called the dilated phase of HCM (d-HCM), which is associated with increased morbidity and mortality. We conducted a retrospective study using an HCM database to clarify the incidence, clinical characteristics, and longterm outcomes of d-HCM. We analyzed an HCM cohort consisting of 434 patients (273 with apical HCM and 161 with non-apical HCM; 18 had obstructive HCM, 16 had dilated HCM, and 127 had other HCM) diagnosed by echocardiography in our hospital between 1991 and 2010 . The follow-up period was 8.4 \pm 6.7 years. The mean age at final follow-up was $67 \pm 14$ years, and 304 patients $(70 \%)$ were men. The mean age of the $16 \mathrm{~d}-\mathrm{HCM}$ patients at the initial visit was $45 \pm 17$ years, the age at final follow-up was 59 \pm 18 years, and 13 were men. Thirteen d-HCM patients developed atrial fibrillation and six patients developed ischemic stroke. Twelve d-HCM patients were implanted with cardiac devices: one pacemaker, nine implantable cardioverter-defibrillators, and two cardiac resynchronization therapy with defibrillator. Five patients died of progressive heart failure at the age of $61 \pm 23$ years. The age at the initial visit and final follow-up were lower and the NYHA class, brain natriuretic peptide levels, and left ventricular function at initial evaluation were worse in the d-HCM group. Univariate analysis demonstrated that a lower age at the initial visit was associated with $\mathrm{d}-\mathrm{HCM}$ (hazard ratio $0.955 / 1$ year increase; $95 \% \mathrm{CI}$ $0.920-0.991, P=0.015)$. In our HCM cohort, the incidence of $\mathrm{d}-\mathrm{HCM}$ was $4 \%$. A high prevalence of atrial fibrillation and cerebral infarction and poor prognosis were noted in this group, despite patients undergoing medication and device implantation. (DOI: 10.2302/kjm.2018-0004-OA)
\end{abstract}

Keywords: hypertrophic cardiomyopathy, systolic dysfunction, dilated phase, prognosis

\section{Introduction}

Hypertrophic cardiomyopathy (HCM) is a genetically determined heart muscle disease characterized by left ventricular hypertrophy of various morphologies with a wide range of clinical manifestations and hemodynamic disturbances. ${ }^{1-5}$ Patients with HCM develop various symptoms, including dyspnea, fatigue, chest pain, palpitations, syncope due to diastolic dysfunction, myocardial ischemia, and atrial or ventricular arrhythmias. For the majority of HCM patients, disease progression is not aggressive. The annual mortality rate of HCM patients is estimated to be about $1 \%$. Sudden cardiac death (SCD) and embolic stroke caused by atrial fibrillation are major causes of death in patients with HCM. However, some patients with HCM develop systolic dysfunction, called dilated-phase HCM (d-HCM), which is associated with increased morbidity and mortality. ${ }^{6-8}$ Dilatation of the 
A

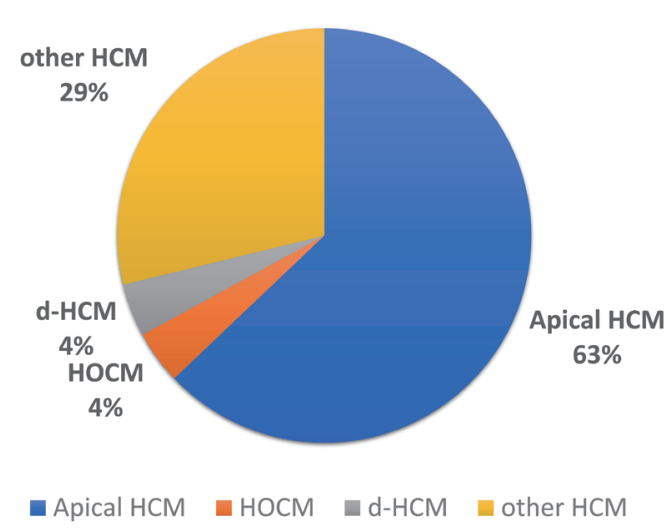

D

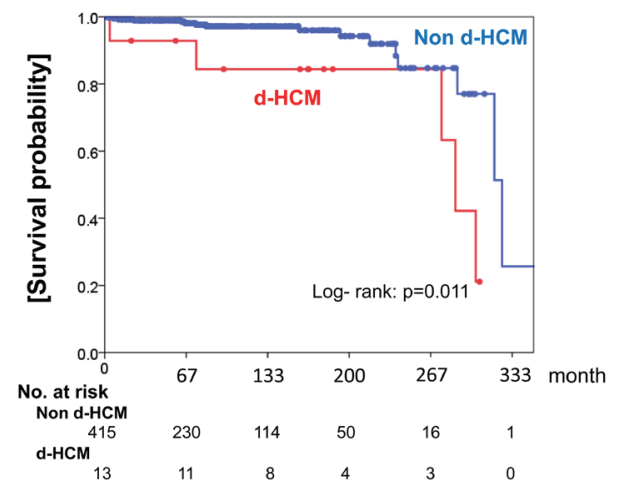

B

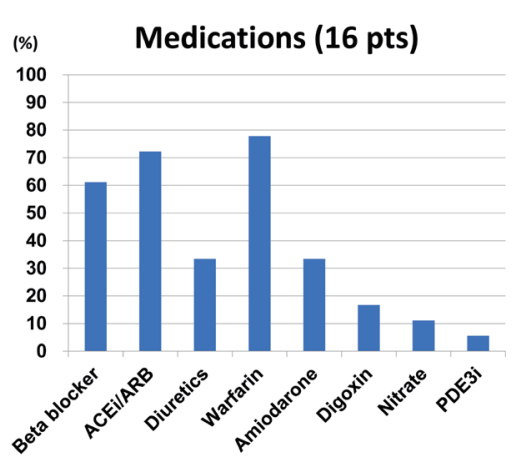

C

Devices (12/16 pts)

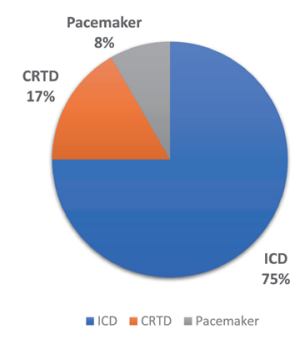

\section{E Time line of d-HCM patients}

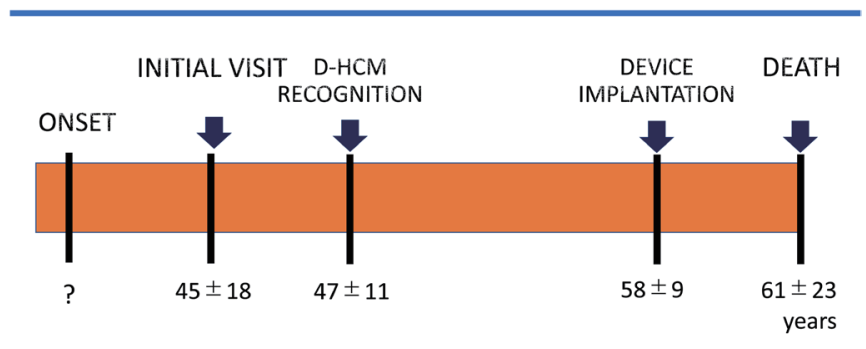

Fig. 1. (A) Breakdown of HCM types in this study. Our HCM cohort consisted of 273 apical HCM cases (63\%) and 161 non-apical HCM cases (37\%). Non-apical HCM cases comprised 18 obstructive HCM cases (4\%), 18 dilated HCM cases (4\%), and 125 other HCM cases (29\%). (B) Drug treatment of the 16 d-HCM patients. ACE, angiotensin converting enzyme inhibitor; ARB, angiotensin receptor blocker; PDE3i, phosphodiesterase-5 inhibitor. (C) Device implantation for the treatment of d-HCM patients. Among the 16 patients, ICDs were implanted in 9 patients, CRTDs were implanted in 2 patients, and a pacemaker was implanted in 1 patient. (D) Long-term survival of d-HCM patients. The Kaplan-Meyer survival curves show the long-term survival rate of d-HCM versus non-d-HCM patients. d-HCM patients had significantly less favorable prognoses than non-d-HCM patients. (E) Timeline of d-HCM patients. The mean ages at the initial visit, at d-HCM recognition, device implantation, and death are indicated. The age at disease onset could not be obtained for these patients.

cardiac cavity and thinning of the ventricular wall as a result of extensive myocardial fibrosis is the underlying pathogenesis of d-HCM. The exact clinical characteristics, proper pharmacological treatment, and long-term prognosis of d-HCM remain unclear. We conducted a retrospective study to investigate the clinical characteristics and predictive factors for the development of d-HCM.

\section{Subjects and Methods}

We retrospectively analyzed a cohort consisting of 434 patients diagnosed with HCM by echocardiography at Keio University hospital between 1991 and 2010. Of the 434 patients, 273 had apical HCM and 161 had non-apical HCM; of the 161 non-apical HCM cases, 18 were obstructive HCM, 16 were dilated HCM, and 127 were other
HCM (Fig. 1A). The baseline demographic and clinical data were collected for all patients using electronic medical records or clinical charts. The clinical information acquired during routine follow-up was also collected. The mean follow-up period was $8.4 \pm 6.7$ years. The mean age at final evaluation was $67 \pm 14$ years, and 304 patients $(70 \%)$ were men. The diagnosis of HCM was based on echocardiographic documentation indicating a hypertrophied left ventricle (LV) in the absence of other cardiac or noncardiac diseases. The diagnosis of d-HCM was based on echocardiographic analysis indicating the development of global systolic dysfunction over time after the initial diagnosis of HCM. This study was approved by the Internal Board of Keio University School of Medicine. (Approval number: 20100171) 
Table 1. Clinical characteristics of the $16 \mathrm{~d}-\mathrm{HCM}$ patients

\begin{tabular}{|c|c|c|c|c|c|c|c|c|c|c|c|c|c|}
\hline No & $\begin{array}{c}\text { Age I/ II } \\
\text { (years) }\end{array}$ & Sex & NYHA & $\begin{array}{c}\text { LVDd } \\
(\mathrm{cm})\end{array}$ & $\begin{array}{l}\text { LVDs } \\
(\mathrm{cm})\end{array}$ & $\begin{array}{c}\text { LVEF } \\
(\%)\end{array}$ & $\mathrm{AF}$ & Stroke & $\begin{array}{c}\text { CHADS2 } \\
\text { /VASc }\end{array}$ & $\mathrm{VT} / \mathrm{VF}$ & Device & $\begin{array}{c}\mathrm{F} / \mathrm{U} \\
\text { (years) }\end{array}$ & $\begin{array}{l}\text { Out-come } \\
\text { (age, years) }\end{array}$ \\
\hline 1 & $48 / 62$ & M & 2 & 7.8 & 6.9 & 24 & - & - & $0 / 0$ & VT & ICD & 14 & Alive \\
\hline 2 & $44 / 52$ & M & 1 & 4.7 & 3.3 & 49 & CAF & + & $4 / 4$ & VF & ICD & 8 & Alive \\
\hline 3 & $63 / 71$ & M & 3 & 5.8 & 5.4 & 19 & CAF & - & $1 / 1$ & VT/VF & ICD & 18 & Dead, 72 \\
\hline 4 & $46 / 63$ & $\mathrm{~F}$ & 3 & 7 & 6.1 & 27 & PAF & - & $1 / 2$ & VT & CRTD & 17 & Alive \\
\hline 5 & $20 / 45$ & $\mathrm{~F}$ & 1 & 4.8 & 3.9 & 39 & CAF & + & $2 / 3$ & - & - & 15 & Alive \\
\hline 6 & $48 / 73$ & M & 2 & 5.7 & 4.9 & 26 & CAF & - & $2 / 2$ & VT & ICD & 25 & Alive \\
\hline 7 & $62 / 68$ & M & 2 & 6.6 & 5.5 & 42 & CAF & + & $1 / 1$ & - & - & 8 & Dead, 75 \\
\hline 8 & $73 / 78$ & M & 1 & 4.6 & 3.2 & 50 & PAF & + & $2 / 3$ & - & - & 5 & Dead, 68 \\
\hline 9 & $26 / 40$ & M & 1 & 6.4 & 4.9 & 55 & CAF & - & $2 / 2$ & VT & ICD & 14 & Alive \\
\hline 10 & $52 / 70$ & M & 2 & 5.5 & 3.7 & 57 & - & - & $1 / 2$ & VT & CRTD & 18 & Alive \\
\hline 11 & $39 / 61$ & M & 1 & 6 & 3.7 & 48 & CAF & + & $1 / 1$ & VT & ICD & 22 & Alive \\
\hline 12 & $73 / 88$ & M & 2 & 5.2 & 4 & 54 & PAF & - & $3 / 4$ & - & - & 15 & Alive \\
\hline 13 & $45 / 68$ & $\mathrm{~F}$ & 2 & 4.5 & 3.5 & 53 & CAF & + & $1 / 2$ & VT & ICD & 23 & Alive \\
\hline 14 & $55 / 68$ & $\mathrm{~F}$ & 1 & 6.1 & 5.1 & 42 & - & - & $3 / 4$ & - & - & 13 & Dead, 69 \\
\hline 15 & $1 / 15$ & M & 1 & 6.6 & 5.6 & 39 & PAF & - & $1 / 1$ & VT & ICD & 14 & Dead, 15 \\
\hline 16 & $44 / 58$ & M & 1 & 6.3 & 5.2 & 36 & PAF & - & $2 / 2$ & VT & ICD & 14 & Alive \\
\hline
\end{tabular}

Age I, age at initial visit; Age II, age at final evaluation; CAF, persistent atrial fibrillation; F/U, follow up; PAF, paroxysmal atrial fibrillation.

\section{Statistical analysis}

Continuous variables are presented as the mean $\pm \mathrm{SD}$, and categorical variables as numbers and proportions. Continuous variables were compared using a MannWhitney U test. Categorical variables were compared between groups using the chi-square test. Univariate analysis was performed, and all variables with a $P$ value of $<0.2$ were included in the multivariate analysis using Cox-regression analysis. The survival rates of the patients were evaluated using the Kaplan-Meier method and compared between groups defined by several different parameters using the log-rank test. Statistical analyses were performed using IBM SPSS Statics software (Version 23). A $P$ value of $<0.05$ was considered statistically significant.

\section{Results}

Table 1 shows the clinical characteristics of the $16 \mathrm{~d}$ HCM patients. Two of the 18 patients initially diagnosed. The mean age of the $16 \mathrm{~d}-\mathrm{HCM}$ patients at the initial visit to our hospital was 45 years, and the mean age at final evaluation was 60 years. Of this group, $72 \%$ were male, the mean ejection fraction (EF) at the time of evaluation was $46 \%$, atrial fibrillation (AF) was noted in $72 \%$, and stroke was noted in $44 \%$. The mean CHADS score was 1.6 , and ventricular tachycardia/ ventricular fibrillation (VT/VF) developed in 11 patients. Finally, 6 of the 16 patients died of progressive heart failure at the mean age of 61 years. The reasons for the initial hospital visit were electrocardiogram (ECG) abnormality identified during a health check in two patients; chest pain in two patients; and syncope, congestive heart failure, palpitation, atrioventricular block, and VT in one patient each.

In most d-HCM patients, adequate medical therapy was administered, as shown in Fig. 1B. Among the 16 d-HCM patients, implantable cardioverter-defibrillators (ICDs) were implanted in 9 patients, cardiac resynchronization therapy with defibrillator (CRTDs) in 2 patients, and a pacemaker in 1 patient, as shown in the Fig. 1C. In most patients, medications, mainly for controlling congestive heart failure and anticoagulation for atrial fibrillation, were strengthened after the transition to d-HCM. Table 2 shows the baseline characteristics at the initial visit of patients with d-HCM and with HCM. Patients were younger at the initial visit and at final evaluation in the dHCM group. The New York Heart Association (NYHA) classification; the CHADS score; and the incidence of syncope, heart failure, AF, stroke, and ICD implantation was higher in the d-HCM group. Table 2 also shows the laboratory, echocardiographic, and ECG data at the initial visit of patients with d-HCM and with HCM. Brain natriuretic peptide (BNP) levels, the left atrial dimension (LAD), left ventricular end-diastolic dimention (LVDd), and left ventricular end-systolic dimention (LVDs) were larger in the d-HCM group. The EF and the amplitude of RV5 plus SV1 were smaller in the d-HCM group. Table 3 shows Cox proportional hazards regression analysis to determine which parameters predict the development of d-HCM. A younger age at the initial visit and at the final evaluation and the presence of syncope and heart failure 
Table 2. Baseline characteristics of patients with d-HCM vs. HCM at initial visit

\begin{tabular}{|c|c|c|c|c|}
\hline & $\begin{array}{l}\text { Overall } \\
(\mathrm{n}=434)\end{array}$ & $\begin{array}{c}\text { d-HCM } \\
(\mathrm{n}=16)\end{array}$ & $\begin{array}{c}\text { Non-d-HCM } \\
(\mathrm{n}=418)\end{array}$ & $P$ value \\
\hline $\mathrm{F} / \mathrm{U}$ period (day) & $2928 \pm 2400$ & $4901 \pm 3084$ & $2862 \pm 2349$ & 0.011 \\
\hline Male, $\mathrm{n}(\%)$ & $304(70)$ & $13(72)$ & $291(70)$ & 0.8369 \\
\hline Age at initial visit (years) & $59.1 \pm 13.9$ & $45.2 \pm 17.3$ & $59.6 \pm 13.5$ & 0.001 \\
\hline Age at final evaluation (years) & $67.2 \pm 14.0$ & $58.6 \pm 17.6$ & $67.5 \pm 13.7$ & 0.026 \\
\hline Body length $(\mathrm{cm})$ & $162.8 \pm 8.9$ & $162.9 \pm 6.9$ & $162.8 \pm 9.0$ & 0.815 \\
\hline Body weight (kg) & $63.9 \pm 12.1$ & $65.5 \pm 12.1$ & $63.8 \pm 12.1$ & 0.616 \\
\hline $\operatorname{BMI}\left(\mathrm{kg} / \mathrm{m}^{2}\right)$ & $24.0 \pm 3.6$ & $23.8 \pm 4.1$ & $24.0 \pm 3.6$ & 0.967 \\
\hline $\mathrm{SBP}(\mathrm{mmHg})$ & $138 \pm 21$ & $139 \pm 20$ & $138 \pm 21$ & 0.108 \\
\hline DBP (mmHg) & $81 \pm 14$ & $78 \pm 13$ & $81 \pm 14$ & 0.542 \\
\hline HR (bpm) & $70 \pm 13$ & $70 \pm 18$ & $70 \pm 13$ & 0.901 \\
\hline NYHA & $1.1 \pm 0.3$ & $1.3 \pm 0.5$ & $1.1 \pm 0.3$ & 0.015 \\
\hline Syncope, n (\%) & $37(9)$ & $4(22)$ & $33(8)$ & 0.038 \\
\hline Heart failure, n (\%) & $96(22)$ & $10(56)$ & $86(21)$ & $<0.001$ \\
\hline Hypertension, n (\%) & $272(63)$ & $8(44)$ & $264(63)$ & 0.1024 \\
\hline Diabetes, n (\%) & $77(18)$ & $4(22)$ & $73(18)$ & 0.6113 \\
\hline $\mathrm{AF}, \mathrm{n}(\%)$ & $162(37)$ & $13(72)$ & $149(36)$ & 0.018 \\
\hline CHADS2 & $1.2 \pm 1.0$ & $1.9 \pm 1.0$ & $1.2 \pm 1.0$ & 0.017 \\
\hline CHA2DS2-VASc & $2.1 \pm 1.5$ & $2.3 \pm 1.1$ & $2.1 \pm 1.5$ & 0.377 \\
\hline Stroke, n (\%) & $45(10)$ & $8(44)$ & $37(9)$ & $<0.001$ \\
\hline Pacemaker, n (\%) & $30(7)$ & $1(6)$ & $29(7)$ & 0.8167 \\
\hline $\mathrm{ICD}, \mathrm{n}(\%)$ & $25(6)$ & $11(61)$ & $14(3)$ & $<0.001$ \\
\hline $\mathrm{FH}$ & $22(5)$ & $1(6)$ & $21(5)$ & 0.9234 \\
\hline \multicolumn{5}{|l|}{ Laboratory data } \\
\hline Creatinine (mg/dl) & $0.9 \pm 0.5$ & $0.9 \pm 0.2$ & $1.0 \pm 0.5$ & 0.689 \\
\hline eGFR (ml/min/1.73m²) & $65 \pm 20$ & $71 \pm 29$ & $65 \pm 20$ & 0.797 \\
\hline $\mathrm{BNP}(\mathrm{pg} / \mathrm{ml})$ & $249 \pm 296$ & $432 \pm 332$ & $241 \pm 292$ & 0.005 \\
\hline \multicolumn{5}{|l|}{ Echocardiographic data } \\
\hline $\mathrm{LAD}(\mathrm{cm})$ & $4.0 \pm 0.7$ & $4.6 \pm 0.8$ & $4.0 \pm 0.7$ & 0.003 \\
\hline LVDd (cm) & $4.7 \pm 0.6$ & $5.3 \pm 0.8$ & $4.7 \pm 0.5$ & 0.003 \\
\hline LVDs (cm) & $2.8 \pm 0.5$ & $3.9 \pm 0.8$ & $2.8 \pm 0.5$ & $<0.001$ \\
\hline $\mathrm{EF}(\%)$ & $78 \pm 8.8$ & $60 \pm 14$ & $78 \pm 7.3$ & $<0.001$ \\
\hline IVS (cm) & $1.3 \pm 0.3$ & $1.3 \pm 0.2$ & $1.3 \pm 0.3$ & 0.785 \\
\hline PW (cm) & $1.0 \pm 0.1$ & $1.0 \pm 0.1$ & $1.0 \pm 0.1$ & 0.952 \\
\hline \multicolumn{5}{|l|}{ ECG parameters } \\
\hline QRS (ms) & $100 \pm 21$ & $113 \pm 33$ & $100 \pm 20$ & 0.081 \\
\hline QT (ms) & $412 \pm 40$ & $414 \pm 57$ & $413 \pm 40$ & 0.911 \\
\hline QTc (ms) & $427 \pm 30$ & $432 \pm 36$ & $426 \pm 29$ & 0.71 \\
\hline RV5+SV1 (mV) & $4.5 \pm 1.7$ & $3.2 \pm 1.4$ & $4.5 \pm 1.7$ & 0.004 \\
\hline
\end{tabular}

BMI, body mass index; CRT, cardiac resynchronization therapy; DBP, diastolic blood pressure; FH, family history; HR, heart rate; IVS, interventricular septum; PW, posterior wall; SBP, systolic blood pressure

were associated with developing d-HCM. The following parameters were associated with the development of dHCM: a higher (eGFR); a larger LAD, LVDd, or LVDs; a smaller EF; and a wide QRS. Fig. 1D shows KaplanMeyer survival curves for d-HCM patients compared with non-d-HCM patients. d-HCM patients had a significantly worse prognosis than that of non-d-HCM patients.
The average timeline of d-HCM patients is presented in Fig. 1E. The mean age at the initial visit was 45 years and that at recognition of d-HCM was 47 years. Device implantation was performed at a mean age of 58 years, and death occurred at a mean age of 61 years. We could not obtain the actual age at disease onset in these patients.

To summarize, in our cohort, the incidence of d-HCM 
Table 3. Cox proportional hazards regression model to predict d-HCM

\begin{tabular}{|c|c|c|c|}
\hline & \multicolumn{3}{|c|}{ Univariate } \\
\hline & HR & $95 \% \mathrm{CI}$ & $P$ \\
\hline Male, n (\%) & 0.788 & $0.245-2.533$ & 0.689 \\
\hline Age at initial visit (1 year increase) & 0.966 & $0.920-0.991$ & 0.021 \\
\hline Age at final evaluation (1 year increase) & 0.937 & $0.905-0.970$ & $<0.001$ \\
\hline Body length (1 cm increase) & 1.035 & $0.943-1.136$ & 0.465 \\
\hline Body weight (1 kg increase) & 1.024 & $0.970-1.082$ & 0.393 \\
\hline BMI $\left(1 \mathrm{~kg} / \mathrm{m}^{2}\right.$ increase $)$ & 0.996 & $0.792-1.252$ & 0.972 \\
\hline SBP (1 mmHg increase) & 0.972 & $0.941-1.004$ & 0.084 \\
\hline DBP (1 mmHg increase) & 0.973 & $0.936-1.012$ & 0.171 \\
\hline Heart rate (1 bpm increase) & 1.002 & $0.956-1.050$ & 0.944 \\
\hline NYHA (1 increase) & 2.214 & $0.859-5.708$ & 0.1 \\
\hline Syncope, $\mathrm{n}$ ( $1 \%$ increase) & 3.75 & $1.148-12.242$ & 0.029 \\
\hline Heart failure, $\mathrm{n}$ ( $1 \%$ increase $)$ & 6.272 & $1.996-19.711$ & 0.002 \\
\hline Hypertension, $\mathrm{n}$ ( $1 \%$ increase) & 2.518 & $0.808-7.847$ & 0.111 \\
\hline Diabetes, $\mathrm{n}(1 \%$ increase $)$ & 1.156 & $0.345-3.871$ & 0.814 \\
\hline $\mathrm{AF}, \mathrm{n}(1 \%$ increase $)$ & 2.861 & $0.889-9.211$ & 0.063 \\
\hline CHADS2 (1 increase) & 1.592 & $0.930-2.728$ & 0.09 \\
\hline CHA2DS2-VASc (1 increase) & 1.196 & $0.796-1.797$ & 0.388 \\
\hline $\mathrm{FH}, \mathrm{n}(1 \%$ increase $)$ & 1.97 & $0.249-15.599$ & 0.521 \\
\hline \multicolumn{4}{|l|}{ Laboratory data } \\
\hline Creatinine $(1 \mathrm{mg} / \mathrm{dl}$ increase $)$ & 0.381 & $0.040-3.589$ & 0.399 \\
\hline eGFR $\left(1 \mathrm{~mL} / \mathrm{min} / 1.73 \mathrm{~m}^{2}\right.$ increase $)$ & 1.022 & $1.001-1.044$ & 0.04 \\
\hline $\mathrm{BNP}(1 \mathrm{pg} / \mathrm{ml}$ increase $)$ & 1.001 & $1.000-1.002$ & 0.13 \\
\hline \multicolumn{4}{|l|}{ Echocardiographic parameters } \\
\hline LAD (1 cm increase) & 1.878 & $1.093-3.224$ & 0.022 \\
\hline LVDd (1 cm increase) & 11.073 & $4.148-29.560$ & $<0.001$ \\
\hline $\mathrm{EF}(1 \%$ increase $)$ & 0.868 & $0.826-0.912$ & $<0.001$ \\
\hline IVS (1 cm increase) & 0.638 & $0.083-4.918$ & 0.667 \\
\hline PW (1 cm increase) & 0.293 & $0.002-35.736$ & 0.617 \\
\hline \multicolumn{4}{|l|}{ ECG parameters } \\
\hline QRS (1 ms increase) & 1.028 & $1.011-1.046$ & 0.001 \\
\hline QT (1 ms increase) & 1.004 & $0.991-1.017$ & 0.521 \\
\hline QTc (1 ms increase) & 1.01 & $0.992-1.027$ & 0.278 \\
\hline RV5+SV1 (1 mV increase) & 0.681 & $0.463-1.000$ & 0.05 \\
\hline
\end{tabular}

CI, confidence interval; HR, hazard ratio.

in $\mathrm{HCM}$ patients was $4 \%$. Of the $16 \mathrm{~d}-\mathrm{HCM}$ patients, 13 developed AF and 6 developed ischemic stroke. Twelve d-HCM patients were implanted with cardiac devices: 1 pacemaker, 9 ICDs, and 2 CRT-Ds. Five d-HCM patients died from progressive heart failure (HF) at a mean age of $61 \pm 23$ years. In the d-HCM group, the age at the initial visit and at the final evaluation were lower, and the NYHA class, BNP levels, and LV function at initial evaluation were worse. Univariate analysis demonstrated that a younger age at the initial visit and a younger age at final evaluation were associated with d-HCM. Catheter ablation was performed in two patients (patient 1 and 11, Table 1) for VT and in one patient for AF (patient 16, Table 1).

\section{Discussion}

The clinical manifestations of HCM can be categorized as those related to heart failure, myocardial ischemia, thromboembolic stroke, palpitations, or SCD due to arrhythmia. The pharmacological treatment of HCM is based on clinical experience and observational research data. Beta blockers and calcium channel blockers (most commonly verapamil) are usually used to treat symptomatic HCM patients. For HCM patients with symptoms of heart failure, diuretics are used with caution due to potential exacerbation of left ventricular outflow tract (LVOT) obstruction. Vasodilators such as nitroglycerin, angioten- 
sin converting enzyme inhibitors, and angiotensin II receptor blockers must also be used with caution in patients with significant LVOT obstruction. Adequate medical therapy was administered to our d-HCM patients. ICD therapy is useful for preventing SCD due to ventricular tachyarrhythmias both for secondary prevention after cardiac arrest and primary prevention with risk factors. Although ICDs were implanted in nine patients, CRTDs were implanted in only two patients. The reason for the low rate of CRTD implantation was that most patients presented here did not fulfil the standard indications of CRTD.

Some patients with HCM develop a systolic dysfunction called d-HCM that is associated with increased morbidity and mortality. Previous studies characterized d-HCM as an LV ejection fraction $<50 \%$ at rest (reflecting global systolic dysfunction) at study entry or during follow-up using two-dimensional echocardiography. ${ }^{9}$ However, there is no definitive definition of d-HCM, and diagnosis is challenging. In the current study, the screening of d-HCM from an HCM registry was based on echocardiographic reports (a formal document in our university hospital) produced by echocardiology specialists. Previous studies have indicated that the incidence of d-HCM is $3.5-5.7 \% .{ }^{6.9}$ The average time from the onset of HCM to the diagnosis of d-HCM was 14 years, and $66 \%$ of patients progressed to death from progressive $\mathrm{HF}, \mathrm{SCD}$, or transplantation over a mean of 2.7 years. SCD occurred at a rate of $11 \% / y e a r$, and the incidence of appropriate ICD shocks was $10 \% /$ year. The predictive factors for $\mathrm{d}$ $\mathrm{HCM}$ are a younger age at initial visit, a family history of $\mathrm{HCM} / \mathrm{d}-\mathrm{HCM} / \mathrm{SCD}$, and a greater wall thickness. ${ }^{6,9} \mathrm{Com}-$ pared with dilated cardiomyopathy (DCM) patients, dHCM patients were more symptomatic at diagnosis; more likely to be male; more likely to have had prior stroke, $\mathrm{AF}$, and VT/VF; and had a higher mortality risk. ${ }^{10,11}$ Doi et al. reported decreases in left ventricular ejection fraction (LVEF) and SV1+RV5 and an increase in left ventricular diastolic dysfunction during the early phase of follow up. ${ }^{12}$ Our study demonstrated that a younger age at the initial visit and at final evaluation, a high eGFR, the presence of syncope, heart failure, worse echocardiographic parameters (LAD, LVDd, EF), a wider QRS duration, and decreased RV5+SV1 were associated with the development of d-HCM.

The exact risk of developing d-HCM from each subtype of HCM has not been clarified. In our cohort, the initial HCM types of d-HCM patients were apical in 3, hypertrophic obstructive cardiomyopathy (HOCM) in 2, and other HCM 13. The risk of developing d-HCM among HOCM patients may be high but was not evaluated in this study.

Matoh et al. reported the usefulness of delayed enhancement (DE) magnetic resonance imaging to differentiate d-HCM and DCM. The HCM patients had more DE than the DCM patients did, and the DE volume correlated to lower global function and local LV function. ${ }^{13}$ Iida et al. examined autopsied d-HCM hearts and found that the percentage area of myocardial fibrosis was higher than that for HCM hearts. ${ }^{14}$ Zen et al. analyzed the plasma levels of soluble Fas (sFas) or Fas ligand, tumor necrosis factor-alpha, and interleukin-6 in patients with d-HCM and found that d-HCM patients with high plasma sFas levels had a significantly higher cumulative incidence of worsening heart failure. ${ }^{15}$ Therefore, proinflammatory cytokines may play a role in the development of d-HCM.

Because more than half of HCM patients have a family history, genetic abnormalities are associated with HCM. ${ }^{5,16-19}$ So far, HCM has been linked to more than 11 genes encoding proteins of contractile filament components of the cardiac sarcomere or the adjacent X-discs. ${ }^{20}$ Mutated beta myosin heavy chain (MYH7) and myosinbinding protein $\mathrm{C}$ (MYBPC3) are the most common disease-causing genes for HCM and account for $30 \%$ of consecutively screened patients with HCM and $70 \%$ of those genotyped patients. The most frequently affected genes in Japanese patients with familial hypertrophic cardiomyopathy were also identified as $M Y B P C 3$ and $M Y H 7 .{ }^{20}$ Additionally, in Japan, there are several reports that suggest a relationship between mutations in the cardiac troponin $\mathrm{T}$ gene (TNNT2) or the cardiac troponin I gene (TNNI3) and d-HCM. ${ }^{21-23}$ Kubo et al. reported that a frameshift mutation in the $M Y B P C$ gene may contribute to the development of d-HCM in elderly patients. ${ }^{8}$ Sato et al. reported a d-HCM patient carrying two different mutations in $M Y B P C 3$ : the Arg835Leu missense mutation and the IVS11+1G $>\mathrm{T}$ splicing mutation. ${ }^{24}$ In this patient, LV reconstruction surgery and CRT were effective for controlling repeat hospitalizations for heart failure. Hitomi et al. identified an R945fs/105 mutation in the $M Y B P C$ gene in six patients with HCM and DCM. They concluded that this mutation may lead to LV systolic dysfunction and to patients suffering from cardiovascular events through mid-life and beyond. ${ }^{25}$ In our d-HCM cohort, a family history of SCD, HCM, and DCM was noted in one patient each. An $M Y B P C 3$ mutation was found in patient 5 (Table 1), but genetic abnormalities were not identified in the other patients.

Despite the poor prognosis of d-HCM described in sporadic and serial case studies, ${ }^{12,26}$ evidence regarding the optimal treatment for d-HCM patients is limited. Heart transplantation is the only definite therapy for drug-resistant d-HCM ${ }^{27}$ However, it is difficult to perform heart transplantation in these patients because there are few heart donors, and recipients are restricted to younger patients in Japan.

The current study had several limitations. This was a retrospective study in a single center. The overall number of patients with d-HCM was small, which complicated the detailed analysis to identify which parameters were predictive factors. It is possible that abnormalities in the genes coding for sarcomeric contractile proteins might be 
involved in the development of d-HCM. However, genetic screening was not performed in all patients in the present study. A systematic study to elucidate d-HCM development, risk stratification, and the management of d-HCM should be attempted.

\section{Conclusion}

In our HCM cohort, the incidence of $\mathrm{d}-\mathrm{HCM}$ was $4 \%$. A high prevalence of atrial fibrillation and cerebral infarctions were noted and prognosis was poor, despite the administration of medication and device implantation.

\section{Acknowledgements}

We are grateful to Mr. John Martin for reading this manuscript. This work was supported by MEXT KAKENHI Grant Number 17K09524.

\section{Conflicts of Interest}

The authors have no conflicts of interest to report.

\section{References}

1. Maron BJ, Towbin JA, Thiene G, Antzelevitch C, Corrado D, Arnett D, Moss AJ, Seidman CE, Young JB; American Heart Association; Council on Clinical Cardiology, Heart Failure and Transplantation Committee; Quality of Care and Outcomes Research and Functional Genomics and Translational Biology Interdisciplinary Working Groups; Council on Epidemiology and Prevention: Contemporary definitions and classification of the cardiomyopathies. Circulation 2006; 113: 1807-1816. PMID:16567565, DOI:10.1161/CIRCULATIONAHA.106.174287

2. Maron BJ, Maron MS: Hypertrophic cardiomyopathy. Lancet 2013 ; 381: 242-255. PMID:22874472, DOI:10.1016/S01406736(12)60397-3

3. Alcalai R, Seidman JG, Seidman CE: Genetic basis of hypertrophic cardiomyopathy: from bench to the clinics. J Cardiovase Electrophysiol 2008; 19: 104-110. PMID:17916152

4. Maron BJ, Maron MS, Semsarian C: Genetics of hypertrophic cardiomyopathy after 20 years: clinical perspectives. J Am Coll Cardiol 2012; 60: 705-715. PMID:22796258, DOI:10.1016/j. jacc.2012.02.068

5. Kimura A: Molecular genetics and pathogenesis of cardiomyopathy. J Hum Genet 2016; 61: 41-50. PMID:26178429, DOI:10.1038/ jhg. 2015.83

6. Biagini E, Coccolo F, Ferlito M, Perugini E, Rocchi G, BacchiReggiani L, Lofiego C, Boriani G, Prandstraller D, Picchio FM, Branzi A, Rapezzi C: Dilated-hypokinetic evolution of hypertrophic cardiomyopathy: prevalence, incidence, risk factors, and prognostic implications in pediatric and adult patients. J Am Coll Cardiol 2005; 46: 1543-1550. PMID:16226182, DOI:10.1016/j. jacc.2005.04.062

7. Thaman R, Gimeno JR, Murphy RT, Kubo T, Sachdev B, Mogensen J, Elliott PM, McKenna WJ: Prevalence and clinical significance of systolic impairment in hypertrophic cardiomyopathy. Heart 2005; 91: 920-925. PMID:15958362, DOI:10.1136/ hrt.2003.031161
8. Kubo T, Kitaoka H, Okawa M, Matsumura Y, Hitomi N, Yamasaki N, Furuno T, Takata J, Nishinaga M, Kimura A, Doi YL: Lifelong left ventricular remodeling of hypertrophic cardiomyopathy caused by a founder frameshift deletion mutation in the cardiac myosin-binding protein $\mathrm{C}$ gene among Japanese. J Am Coll Cardiol 2005; 46: 1737-1743. PMID:16256878, DOI:10.1016/j. jacc.2005.05.087

9. Harris KM, Spirito P, Maron MS, Zenovich AG, Formisano F, Lesser JR, Mackey-Bojack S, Manning WJ, Udelson JE, Maron BJ: Prevalence, clinical profile, and significance of left ventricular remodeling in the end-stage phase of hypertrophic cardiomyopathy. Circulation 2006; 114: 216-225. PMID:16831987, DOI:10.1161/CIRCULATIONAHA.105.583500

10. Hamada T, Kubo T, Kitaoka H, Hirota T, Hoshikawa E, Hayato K, Shimizu Y, Okawa M, Yamasaki N, Matsumura Y, Yabe T, Takata J, Doi YL: Clinical features of the dilated phase of hypertrophic cardiomyopathy in comparison with those of dilated cardiomyopathy. Clin Cardiol 2010; 33: E24-E28. PMID:20641106, DOI:10.1002/clc.20533

11. Goto D, Kinugawa S, Hamaguchi S, Sakakibara M, Tsuchihashi-Makaya M, Yokota T, Yamada S, Yokoshiki H, Tsutsui H, JCARE-CARD Investigators: Clinical characteristics and outcomes of dilated phase of hypertrophic cardiomyopathy: report from the registry data in Japan. J Cardiol 2013; 61: 65-70. PMID:23078864, DOI:10.1016/j.jjcc.2012.08.010

12. Doi K, Toda G, Iliev ILIEV I, Hayano M, Yano K: Clinical analysis of hypertrophic cardiomyopathy which evolved into dilated phase during long-term follow-up. Jpn Heart J 1999; 40: 579-587. PMID:10888378, DOI:10.1536/jhj.40.579

13. Matoh F, Satoh H, Shiraki K, Saitoh T, Urushida T, Katoh H, Takehara Y, Sakahara H, Hayashi H: Usefulness of delayed enhancement magnetic resonance imaging to differentiate dilated phase of hypertrophic cardiomyopathy and dilated cardiomyopathy. J Card Fail 2007; 13: 372-379. PMID:17602984, DOI:10.1016/j. cardfail.2007.02.001

14. Iida K, Yutani C, Imakita M, Ishibashi-Ueda H: Comparison of percentage area of myocardial fibrosis and disarray in patients with classical form and dilated phase of hypertrophic cardiomyopathy. J Cardiol 1998; 32: 173-180. PMID:9783238

15. Zen K, Irie H, Doue T, Takamiya M, Yamano T, Sawada T, Azuma A, Matsubara H: Analysis of circulating apoptosis mediators and proinflammatory cytokines in patients with idiopathic hypertrophic cardiomyopathy: comparison between nonobstructive and dilated-phase hypertrophic cardiomyopathy. Int Heart J 2005; 46: 231-244. PMID:15876807, DOI:10.1536/ihj.46.231

16. Seidman JG, Seidman C: The genetic basis for cardiomyopathy: from mutation identification to mechanistic paradigms. Cell 2001; 104: 557-567. PMID:11239412, DOI:10.1016/S00928674(01)00242-2

17. Kimura A: [Molecular pathogenesis of primary cardiomyopathy and calcium sensitivity]. Clin Calcium 2013; 23: 551-560. PMID:23545745

18. Kimura A: Molecular basis of hereditary cardiomyopathy: abnormalities in calcium sensitivity, stretch response, stress response and beyond. J Hum Genet 2010; 55: 81-90. PMID:20075948, DOI:10.1038/jhg.2009.138

19. Kimura A. Molecular etiology and pathogenesis of hereditary cardiomyopathy. Circ J 2008;72 Suppl A:A38-48.

20. Otsuka H, Arimura T, Abe T, Kawai H, Aizawa Y, Kubo T, Kitaoka H, Nakamura H, Nakamura K, Okamoto H, Ichida F, Ayusawa M, Nunoda S, Isobe M, Matsuzaki M, Doi YL, Fukuda K, Sasaoka T, Izumi T, Ashizawa N, Kimura A: Prevalence and distribution of sarcomeric gene mutations in Japanese patients with familial hypertrophic cardiomyopathy. Circ J 2012;76(2):453-61. 
21. Fujita E, Nakanishi T, Nishizawa T, Hagiwara N, Matsuoka R: Mutations in the cardiac troponin $\mathrm{T}$ gene show various prognoses in Japanese patients with hypertrophic cardiomyopathy. Heart Vessels 2013; 28: 785-794. PMID:23494605, DOI:10.1007/ s00380-013-0332-3

22. Kimura A, Harada H, Park JE, Nishi H, Satoh M, Takahashi M, Hiroi S, Sasaoka T, Ohbuchi N, Nakamura T, Koyanagi T, Hwang TH, Choo JA, Chung KS, Hasegawa A, Nagai R, Okazaki O, Nakamura H, Matsuzaki M, Sakamoto T, Toshima H, Koga Y, Imaizumi T, Sasazuki T: Mutations in the cardiac troponin I gene associated with hypertrophic cardiomyopathy. Nat Genet 1997; 16: 379-382. PMID:9241277, DOI:10.1038/ng0897-379

23. Kokado H, Shimizu M, Yoshio H, Ino H, Okeie K, Emoto Y, Matsuyama T, Yamaguchi M, Yasuda T, Fujino N, Ito H, Mabuchi $\mathrm{H}$ : Clinical features of hypertrophic cardiomyopathy caused by a Lys183 deletion mutation in the cardiac troponin I gene. Circulation 2000; 102: 663-669. PMID:10931807, DOI:10.1161/01. CIR.102.6.663
24. Sato A, Sakamoto N, Ando K, Kaneshiro T, Uekita H, Sugimoto K, Yamaki T, Kunii H, Nakazato K, Suzuki H, Saitoh S, Sato M, Tamagawa K, Arimura T, Kimura A, Takeishi Y: Dilated phase of hypertrophic cardiomyopathy caused by two different sarcomere mutations, treated with surgical left ventricular reconstruction and cardiac resynchronization therapy with a defibrillator. Intern Med 2012; 51: 2559-2564. PMID:22989827, DOI:10.2169/internalmedicine. 51.7684

25. Hitomi N, Kubo T, Kitaoka H, Hirota T, Hamada T, Hoshikawa E, Hayato K, Okawa M, Kimura A, Doi YL: A frameshift deletion mutation in the cardiac myosin-binding protein $\mathrm{C}$ gene associated with dilated phase of hypertrophic cardiomyopathy and dilated cardiomyopathy. J Cardiol 2010; 56: 189-196. PMID:20605413, DOI:10.1016/j.jjcc.2010.04.003

26. Kawai M, Kihara Y, Hasegawa K, Matsumori A, Sasayama S: Dilated phase of hypertrophic cardiomyopathy with mid-ventricular obstruction after 20-year follow-up. Jpn Circ J 2000; 64: 623-626. PMID:10952162, DOI:10.1253/jcj.64.623

27. Spirito P, Seidman CE, McKenna WJ, Maron BJ: The management of hypertrophic cardiomyopathy. N Engl J Med 1997; 336: 775-785. PMID:9052657, DOI:10.1056/NEJM199703133361107 